\title{
Attitude of Higher Secondary School Teachers towards the Use of Magic Tricks in the Classroom
}

\author{
Dr. Muniisvaran Kumar \\ Sultan Idris Education University, Malaysia \\ Dr. Sagy John \\ Eritrea Institute of Technology, Eritrea \\ Dr. Franklin Thambi Jose. S \\ SultanIdris Education University, Malaysia
}

Doi: 10.36941/ajis-2020-0o22

\begin{abstract}
Research shows that motivation and engagement are essential for effective learning and it is not an easy task to achieve. The latest technique to attract the students is to integrate humour in classroom teaching. Humour is an often-overlooked skill in teaching as the teachers are not trained in the use of humour and it is not a part of any curriculum and they consider teaching is a serious business and they are not supposed to be entertainers. Magic tricks represent one of the humour items that can be effectively used at all levels of teaching from schools to colleges. Also, it can be used as teaching aid and it can be termed as 'ice-breaker'. The 'Primacy and recencey effect' and 'Zeigarnick effect' gives a strong theoretical basis for the use of magic as an 'ice-breaker' in the class. Magic tricks have many benefits in teaching such as it can break the monotony of a lecture, captures and retains student attention, make the students more receptive, expands student comprehension, increases opportunity for memory retention, creates nurturing environment for learning, improving communication skills, providing stress relief and creating an environment of trust. Teachers' attitude towards the use of magic tricks in the class has an effect on their performance. An attitude survey was conducted to see the attitude of higher secondary school teachers towards the use of magic tricks in the classroom by using an attitude scale. The data collection for this study is limited to only 165 teachers who belong to higher secondary school of Wayanad District of Kerala, South India. Subject-wise comparison of the teachers also was done. The study exposes that the teachers' positive attitude towards the use of humour especially magic tricks in the classroom. Magic tricks and other humour items are not a compulsory skill to be mastered and used on a regular interval by all teachers in the class; instead if it is used appropriately, it will definitely add an additional golden feather in the teacher's cap.
\end{abstract}

Keywords: Humour, magic tricks, teaching, communication

\section{Introduction}

Teaching and learning processes have changed a lot due to the advancement of technology and the new methods implemented in the classrooms. Also, after the shift of classroom teaching from teacher oriented to learner oriented which took place in the two decades, there was a constant discussion 
among the researchers, teachers, educationalists, psychologists, etc. how to develop teaching and learning processes more effective than the previous ages. In the arena of learner-centred pedagogy, if one wants to excel in the field of teaching, he or she must try a variety of techniques to reach students, and have additional skills or resources such as magic tricks, puzzles, humorous cartoons, humorous anecdotes, interesting stories, citing real-life examples, etc. in his or her teaching armoury to provide the content in a way that will be remembered and keep students engaged in learning. Keeping the students motivated and engaged in learning is not an easy task for many teachers. One way to engage students is to incorporate humour in teaching. Humour is an often-overlooked skill in teaching as the teachers are not trained in the use of humour and it is not a part of any curriculum and they consider teaching is a serious business and they are not supposed to be entertainers.

Magic is one of the twenty modalities of humours identified by Lesser \& Pearl (2008) that can be effectively used at all levels of teaching from schools to colleges. It is among the oldest of the performing arts which has the ability to capture and hold the inquisitive minds of children and adults alike. Elder Kevin \& others (2019) say that, 'Use of magic in the classroom is a growing trend with educators at all levels. It can be used as a teaching tool as well as an 'ice-breaker'.' The 'Primacy and Recency Effect' as well as 'Zeigarnick Effect' gives a strong theoretical basis for the use magic as an 'ice-breaker' in the class. Use of magic is a very innovative way to maximize the chances for strong and lasting engagement and motivation of students (Hatziapostolou, T, 2019). Magic tricks are not simply used in the classrooms, instead it is an ice break which is used in-between a lecture to make sure that the students are actively learning or listening the lecture.

\section{Significance of the Study}

Attitude is the individual's prevailing tendency to respond favourably or unfavourably to an object (person or group of people, institutions or events). Attitudes are entrenched in experience what each individual can see, can hear, can think and can do. The teacher is the important person in the classroom who sets the atmosphere for creative thinking and learning. Teachers' attitude towards the use of humour in the class has an effect on their performance. Humour in the classroom can take many forms like jokes, puzzles, funny stories, humorous comments and other humorous items like magic tricks. Magic tricks as well as puzzles can be effectively used at all levels of teaching from schools to colleges (John, Sagy et.al.,2012).

In India, especially in Kerala, only a few teachers use magic tricks as a humour item in classrooms. Whether it is their negative attitudes towards its use or some other reasons hinder them using magic in the class has to be studied. Studies relating to attitude towards the use of magic tricks in teaching are not carried out in India. Hence a study is conducted to see the attitude of higher secondary school teachers towards the use of magic tricks in the classroom.

\section{Benefits of Using Magic Tricks in Teaching}

Student classroom performance is strongly influenced by relationship with teacher and use of magic trick is one method by which teacher can build good rapport with them. Kuhn \& Rensink (2008), say that "in classrooms, students will be less intimidated and less inhibited about asking questions or making comments. Magic tricks depend on assumptions about the world and magicians skilfully violate these assumptions to create mysteries' A teacher who effectively prepares and uses magic in the classroom will find that teaching is more fun and enjoyable. A central part of magic is the experience of wonder that arise from perceiving an event that is apparently impossible which leads to humour, amazement and surprise. Students tend to value and appreciate teachers who can effectively use magic in their teaching. It has been found that when people have more fun on their job, they perform better. Magic can increase the student perception of teacher credibility if it enhances learning. Further, magic can keep the students awake, energized and excited. 'Being able to perform magic and illusions for teaching purposes is undoubtedly an exciting fun, and a new strategy which 
has a strong effect on learners regardless of age, gender or race,' says Hatziapostolou, T (2019).

Moreover, humour is one of the effective means of enhancing students' motivation to study any subject and to enhance group cohesion. Most of the students appreciate funny stories, comments, jokes, magical tricks and professional humour (John, Sagy 2019).

Use of humour (magic tricks) is highly effective especially in dread courses (Khairul et.al.2008). The use of magic tricks seems to have a positive effect not only on learning but also on classroom management by promoting relaxation and creating a comfortable classroom climate.

\section{Objectives of the Study}

This study is based on 4 objectives and they are:

1. To develop a tool to measure the attitude of teachers towards the use of magic tricks in teaching.

2. To identify the attitude of teachers towards the use of magic tricks in teaching.

3. To identify the influence of gender, teaching experience, type of school and teaching subject on the attitude of teachers towards the use of magic tricks in teaching.

\section{Method, Population and Sample}

The present study used survey as the method of research. Survey method is based on interviews or questionnaire.

The population identified for the study included Higher Secondary school teachers of Wayanad district, Kerala, India. Wayanad district is one of the districts of Kerala state. Kerala state is situated in the southern part of India. In Wayanad district, there are three types of higher secondary schools based on management, which include government, government aided and unaided. More than $95 \%$ of the schools come under government and government aided schools. All these schools follow the same curriculum and the students are to write the common public examination.

The study was limited to 165 teachers of higher secondary schools from Wayanad District of Kerala State, India. Random sampling method was used in this study to select three groups of higher secondary school teachers i.e., science teachers, social science teachers and language teachers. Science teachers included higher secondary school teachers who teach mathematics, physics, chemistry or biology. Social science teachers include those who teach sociology, political science and other humanities subjects. Language teachers included those who teach languages like Malayalam, Hindi and English to higher secondary school students. 55 teachers from each group was selected on a random basis to form the final sample of 165 teachers. Teachers from government and government aided schools only were selected for the study. Un-aided school teachers were not included as their number was very few.

\section{Tool Used}

An attitude scale: The investigator developed and validated an attitude scale with items related to the various aspects using magic tricks in teaching. There were a total of 26 statements. Out of this only 21 statements were favourable and the other five were unfavourable statements. Each statement was measured on a five point scale and total score that can be taken on this scale ranged from twenty -six to one hundred and thirty (26-130). There were provisions to write features like gender, type of school, years of teaching experience etc. along with the response sheet.

\section{Data Collection}

As mentioned earlier, data were collected from the Higher Secondary School Teachers of Wayanad District, Kerala State, India. The data were analysed using the scale to measure the attitude of school 
teachers towards the use of magic or icebreaker while teaching. Attitude scores were calculated by counting the scores obtained for each item in the tool.

\section{Statistical Techniques Used}

The statistical techniques used were Preliminary statistics and test of significance of differences between means.

\section{Data Analysis and Results}

The collected data were analysed and tabulated with the mean value and standard deviation which were calculated for the total samples and the sub samples. The difference between the mean scores of sub groups was tested by finding the t-value. The results of the test of significance are given in the following tables.

Table 1: Preliminary statistics of the total sample on attitude towards the use of magic tricks in teaching

\begin{tabular}{|c|c|c|c|c|c|c|}
\hline Mean & Median & Mode & Skewness & Kurtosis & SD & N \\
\hline 100.95 & 101 & 100 & -4.5 & 41.15 & 9.89 & 165 \\
\hline
\end{tabular}

The above table explains the mean, median, mode, skewness, kurtosis, Standard Deviation (SD) and total number of samples $(\mathrm{N})$. From the above table it is clear that the selected sample of higher secondary school teachers have a high positive attitude towards the use of magic in the class. Individual score can range from 26 to 130 but the mean attitude score 100.95 shows a positive attitude.

Hypothesis 1: According to hypothesis 1, there is no significant mean score difference in attitude between male and female teachers of this study. Here, 66 male teachers and 99 female teachers are selected for the study as informants from Higher Secondary School Teachers of Wayanad District, Kerala State, India. When mean for these are calculated, it showed as 99.76 and 101.76 respectively. Moreover, standard deviation is calculated as 13.11 for male teachers and 6.93 for female teachers. The t-value is calculated as 1.13. The level of significant is low and thus this hypothesis is substantiated.

Table 2: Mean score difference in attitude between Male and Female Teachers of the study

\begin{tabular}{|l|c|c|c|c|c|}
\hline Group & $\mathrm{N}$ & Mean & SD & t-value & Level of significance \\
\hline Male & 66 & 99.76 & 13.11 & \multirow{2}{*}{1.13} & \multirow{2}{*}{ Not Significant at o.05 level } \\
\cline { 1 - 4 } Female & 99 & 101.76 & 6.93 & & \\
\hline
\end{tabular}

The above table shows the difference in attitude between the male and female teacher samples. The number of samples mentioned in table-2 is 66 male and 99 female teachers. Also, it shows the mean score difference in attitude between Male and female teachers of the study were not significant at 0.05 level. Hence the study accepts the hypothesis-1. Gender does not have a significant influence the attitude towards the use of magic in teaching.

Hypothesis 2: Hypothesis 2 shows that there is no significant mean score difference in attitude between Government School Teachers and Government Aided school teachers of the study. To substantiate this hypothesis, 88 government school teachers and 77 government aided school teachers are involved. When mean is calculated there is no much difference. The calculated mean are 101.15 and 100.73. The standard calculated are 6.94 for government teachers and 12.48 for government aided teachers. Accordingly, this hypothesis is shown. 
Table 3: Mean score difference in attitude between Government School Teachers and Government aided school teachers of the study

\begin{tabular}{|l|c|c|c|c|c|}
\hline School Type & $\mathrm{N}$ & Mean & SD & t-value & Level of significance \\
\cline { 1 - 4 } Govt. & 88 & 101.15 & 6.94 & \multirow{2}{*}{0.26} & \multirow{2}{*}{ Not Significant at o.05 level. } \\
\hline Aided & 77 & 100.73 & 12.48 & \\
\hline
\end{tabular}

The above table shows that 88 government school teachers and 77 government aided school teachers are selected for hypothesis 2. Moreover, table-3 displays the mean score difference in attitude between Government School Teachers and Government Aided School Teachers. The mean difference is not significant at 0.05 level. Hence the study accepts the hypothesis-2. Further, it can infer that the type of school does not have a significant influence in the attitude of use magic tricks in teaching.

Hypothesis 3: In this hypothesis, there is no significant mean score difference in attitude between Science Teachers and Social science Teachers of the study from Higher Secondary School Teachers of Wayanad District, Kerala State, India. For this, 55 science teachers and 55 social science teachers are chosen. The mean are calculated as 98.42 and 100.57 respectively. The $t$-value is calculated as 0.99. Moreover, the level of significance is 0.05 . Consequently the hypothesis is validated.

Table 4: Mean score difference in attitude between Science Teachers and Social science Teachers of the study

\begin{tabular}{|l|c|c|c|c|c|}
\hline Group & N & Mean & SD & t-value & Level of significance \\
\cline { 1 - 4 } Science Teachers & 55 & 98.42 & 7.37 & \multirow{2}{*}{0.99} & \multirow{2}{*}{ N.S. at o.o5 level } \\
\cline { 1 - 3 } Social science Teachers & 55 & 100.57 & 13.56 & \\
\hline
\end{tabular}

Table- 4 shows that 55 science teachers and 55 social science teachers are involved for this study. Also, the mean score difference in attitude between Science Teachers and Social Science Teachers is provided. The mean score difference is not significant at 0.05 level. Hence hypothesis- 3 is accepted. Science Teachers and Social Science Teachers have similar positive attitude towards the use of magic in the class.

Hypothesis 4: This hypothesis shows that there is no significant mean score difference in attitude between Science teachers and language teachers of the study from Higher Secondary School Teachers of Wayanad District, Kerala State, India. To substance this, 55 science teachers and 55 language teachers are selected. The attitude between these teachers is calculated to find out the mean. The results are calculated as 98.42 and 103.96 respectively. The standard derivation is calculated as 7.37 for science teachers and 6.54 for language teachers. The t-value is 4.17 and the level of significance is 0.01 . In such a way the hypothesis is verified.

Table 5: Mean score difference in attitude between Science Teachers and Language Teachers of the study

\begin{tabular}{|l|c|c|c|c|c|}
\hline Group & $\mathrm{N}$ & Mean & SD & t-value & Level of significance \\
\cline { 1 - 4 } Science Teachers & 55 & 98.42 & 7.37 & \multirow{2}{*}{4.17} & \multirow{2}{*}{ Significant at o.o1 level } \\
\cline { 1 - 3 } Language Teachers & 55 & 103.96 & 6.54 & \\
\hline
\end{tabular}

As mentioned in table- 5 , 55 science teachers and 55 language teachers are selected for this study. Moreover, the table shows clearly that mean score difference in attitude between Science Teachers and Language Teachers is found. The mean score difference is significant at o.or level. Hence the study rejects hypothesis-4. It can be concluded as Language Teachers have more positive attitude than Science Teachers. 
Hypothesis 5: This hypothesis shows that there is no significant mean score difference in attitude between Social Science Teachers and Language Teachers of the study from Higher Secondary School Teachers of Wayanad District, Kerala State, India. For this, 55 social science teachers and 55 language teachers are selected and mean was calculated. The calculated mean are 100.47 and 103.96. Also, the standard deviation 13.56 for social science teachers and 6.54 for language teachers. Since the level of significance is 0.05 , there is no difference in attitude between the two set of teachers. Accordingly, the hypothesis is substantiated.

Table 6: Mean score difference in attitude between Social Science Teachers and Language Teachers of the study

\begin{tabular}{|l|c|c|c|c|c|}
\hline Group & $\mathrm{N}$ & Mean & SD & t-value & Level of significance \\
\hline Social Science Teachers & 55 & 100.47 & 13.56 & \multirow{2}{*}{1.72} & \multirow{2}{*}{ N.S. at 0.05 level } \\
\cline { 1 - 3 } Language Teachers & 55 & 103.96 & 6.54 & & \\
\hline
\end{tabular}

To find out the mean, 55 social science teachers and 55 language teachers are selected for this study. Table -6 shows that mean score difference in attitude between Social Science Teachers and language Teachers. The mean score difference is not significant at 0.05 level. Hence the research accepts the hypothesis- 5 .

Hypothesis 6 : According to hypothesis 6, there is no significant mean score difference in attitude between teachers with experience below eight (8) years and eight to fifteen (8-15) years from Higher Secondary School Teachers of Wayanad District, Kerala State, India. For this, 65 teachers with below eight years of experience and 57 teachers with eight to fifteen years of experience are selected. The mean are calculated as 101.35 and 99.25 respectively. Also, the standard deviation is calculated as 6.84 for teachers with experience below eight (8) years and 13.37 for teachers with eight to fifteen years. When level of significance is identified, it has a difference of only 0.05 level. In the way, the hypothesis is verified.

Table 7: Mean score difference in attitude between teachers with experience Below eight years and Eight to fifteen (8-15) years

\begin{tabular}{|l|c|c|c|c|c|}
\hline Teaching experience & $\mathrm{N}$ & Mean & SD & t-value & Level of significance \\
\hline Below eight (8) years & 65 & 101.35 & 6.84 & \multirow{2}{*}{1.07} & \multirow{2}{*}{ N.S. at o.o5 level } \\
\cline { 1 - 4 } Eight to fifteen (8-15) years & 57 & 99.25 & 13.37 & & \\
\hline
\end{tabular}

65 Teachers with below eight years of experience and 57 teachers with eight to fifteen years of experience are selected for this study. From the above table it is clear that the mean score difference in attitude between teachers with experience below eight years and that of eight to fifteen years. The mean score difference is not significant at 0.05 level. Hence the hypothesis is accepted.

Hypothesis 7: In hypothesis 7, it reveals that, there is no significant mean score difference in attitude between teachers with experience eight $t$ to fifteen years (8-15) and more than fifteen (15) years from Higher Secondary School Teachers of Wayanad District, Kerala State, India. To substantiate this, 57 school teachers with eight to fifteen years of experience and 43 school teachers with more than fifteen years of experience are selected and the mean is calculated. The mean values are 99.25 and 102.6. The standard deviation is calculated as 13.37 for teachers with eight to fifteen years of experience and 8.07 for teachers with more than fifteen years of experience and the significance level is 0.05 . The hypothesis is proven by this calculation. 
Table 8: Mean score difference in attitude between teachers with experience Eight to fifteen (8-15) years and more than fifteen (15) years

\begin{tabular}{|l|c|c|c|c|c|}
\hline Teaching experience & $\mathrm{N}$ & Mean & SD & t-value & Level of significance \\
\cline { 1 - 4 } Eight to fifteen (8-15) years & 57 & 99.25 & 13.37 & \multirow{2}{*}{1.56} & \multirow{2}{*}{ N.S. at o.05 level } \\
\cline { 1 - 3 } More than fifteen years & 43 & 102.6 & 8.07 & \\
\hline
\end{tabular}

This table shows that 57 teachers with eight to fifteen years of experience and 43 teachers with more than fifteen years of experience are selected for this study. Moreover, from the above table one can understand that the mean score difference in attitude between teachers with experience eight to fifteen years and that of more than fifteen years are clearly seen. The mean score is not significant at 0.05 level. Hence the hypothesis is accepted.

Hypothesis 8: This hypothesis reveals that, there is no significant mean score difference in attitude between teachers with experience below eight (8) years and more than fifteen (15) years from Higher Secondary School Teachers of Wayanad District, Kerala State, India. To substantiate this hypothesis, 65 teachers with below eight years of experience and 43 school teachers with more than fifteen years of experience are chosen. The mean is calculated as 101.35 and 102.6. Further, the standard deviation is calculated as 6.84 for teachers with below eight years of experience and 8.07 for teachers more than fifteen years of experience. The t-value is calculated as 0.84 for the teachers' attitude. Since there is no difference in level of significance that is 0.05 level, this hypothesis is ascertained. Thus, the hypothesis is substantiated.

Table 9: Mean score difference in attitude between teachers with experience Below eight years and more than fifteen years

\begin{tabular}{|l|c|c|c|c|c|}
\hline Teaching experience & $\mathrm{N}$ & Mean & $\mathrm{SD}$ & t-value & Level of significance \\
\cline { 1 - 4 } Below eight (8) years & 65 & 101.35 & 6.84 & \multirow{2}{*}{0.84} & \multirow{2}{*}{ N.S. at o.o5 level } \\
\hline More than fifteen years & 43 & 102.6 & 8.07 & \\
\hline
\end{tabular}

65 teachers with eight years of experience and 43 teachers with more than 15 years of experience are selected for this study and are given in table-9. Also, the above table shows that mean score difference in attitude between teachers with experience below eight years and that of more than fifteen years is not significant at 0.05 level. Hence the hypothesis is accepted. Teaching experience does not have a significant influence on the attitude of use magic tricks in the classroom.

\section{Conclusion and Educational Implications of the Study}

A positive attitude towards the use of magic tricks in the classroom was found among the Higher Secondary School Teachers. Gender, teaching experience and type of the school does not have significant influence in attitude towards the use of magic tricks in teaching. Language Teachers have a significant high attitude than the Science Teachers of the study. However, both the Social Science teachers and language teachers have similar attitude with regard to the use of magic in classrooms. The results of the study reveals that it is not because of negative attitude, but due to some other factors hinder the higher secondary teachers from use of magic in teaching. Perhaps, they may not be trained in this area or magic resources may not be available to them. Further research is required in this area. From the literature review, one can conclude that using magic tricks can be used to increase teachers' credibility, likeability, professional image and teaching effectiveness.

\section{References}

Bowman, R.P. (1986). The magic counsellor: using magic tricks as tools to teach children guidance lessons. Elementary School Guidance and Counselling, 21: 128-138. 
Bowman, R.P. (2002). Fifty magic tricks using common objects that teach children strategies for success. Youth light; Chapin.

Bowman, R.P. (2004).The magic counsellor: the twenty five best purchasable magic tricks with unforgettable guidance lessons for kids. Youth light: Chapin.

Breathe (2015). Breathe Magic. Retrieved from http://breatheahr.org/breathe-magic/

Devadoss, S. \& Foltz,J. (1996). Factors influencing class attendance and performance. American Journal of Agricultural Economics, 499-507.

Elder, Kevin., Deviney, David., Mackinno, Ronald and Dyer, John. (2019).Using illusions in the classroom: Principles, Best practices, and Measurement. Retrieved on 12/03/2019 from https://www.researchgate.net

Frith, G. H., \& Walker, J. C. (1983). Magic as motivation for handicapped students. Teaching Exceptional Children, 15(2), 108-110.

Haub, E.K. (2001). Disappearing-reappearing magic trick: a new twist to an old liquid nitrogen demonstration. Chemistry Education.78(1): 46 doi 10.1021/edo78p46.

Hatziapostolou, Tahnos. (2019). Learning begins with wonder-Teaching with magic. Retrieved from http://city.academic.gr/csd/hatziapostolou/Magician

John, Sagy. (2011). Amazing techniques to grab and hold the attention of audience. Paper presented at the E.I.T.'s seminar held at College of Education,Mainefhi Eritrea Institute of Technology, Eritrea.

John, Sagy., Jose, Franklin Thambi \& Kumar, Satheesh (2012). Effective use of humour in college classrooms. Paper presented in the International Education meet on 'Education for global excellence' held at Mar Theophilus Training college and Council for Teacher Education, Thiruvananthapuram, Kerala.

John, Sagy. (2019). Teach with magic: An innovative strategy. Paper presented in the international conference on 'Professionalism:Challenges and innovation in science and humanities held at Muslim College of Education; Thiruvithamcode, Kanyakumari District, Tamil Nadu on $28^{\text {th }}$ and $29^{\text {th }}$ March 2019.

Khairul Firhan Yusob, Khairunisa Nikman and Ahmad Nazri Jelani (2018). Lecturers' Perceptions of the Benefits of Using Humour in Classroom. In the LSP International Journal Vol5, Issue.1, p49-58

Kuhn, G. \& Land M. K. (2006). There's more to magic than meets the eye. Current Biology, 16, 950-951.

Kuhn, G., Amlani, A. A., \& Rensink R. A. (2008). Towards a science of magic. Trends in Cognitive Science. 12 (9), 349-354.

Lesser, L.M. \& Glickman, M.E. (2009).Using magic in the teaching of probability and statistics. Model Assisted Statistics and Applications. 4:265-274.

Levin, D. (2007). Magic arts counselling: the tricks of illusion as intervention. Georgia School Counsellors Association Journal. 23:14-23.

Muniisvaran, K, Vijayalakshmi, J. and Franklin Thambi Jose. S. (2018). Psychological Support For Mental Health Of Mothers To Childhood The Children With Disability. International Journal of Asian Social Science, 8(12), 1186-1191. 1191. DOI: 10.18488/journal.1.2018.812.1186.1191

Kartheges Ponniah, Kingston Pal Thamburaj and Sammikkanu Jabamoney Isak Samuvel (2017). Language attitude among Tamil language teachers. International Journal of Advanced and Applied Sciences, 4 (6), 142-147. (eISSN 2313-3424, Print ISSN 2313-626X)

Kartheges Ponniah, Ilangkumaran Sivanadhan, Muniisvaran Kumar, and Pooveneswaran Nadarajan. (2019). Implementation of the 21st century learning in learning and facilitation of Thirukural in Tamil primary schools. International Journal of Advanced and Applied Sciences, 6(1), 43-50. (e-ISSN 2313-3424, Print ISSN 2313-626X).

Kartheges Ponniah, Muniisvaran Kumar, Sasigaran Moneyam, and Ilangkumaran Sivanadhan. (2019). The teaching of Thirukkural based on HOTS among the students of Tamil primary schools in the state of Perak. International Journal of Advanced and Applied Sciences, 6(2), 94-101. (e-ISSN 2313-3424, Print ISSN 2313-626X).

Solomon,P.R. (1980) . Perception, illusion, and magic. Teaching of Psychology. 7:3-7.

Tamblyn, Doni. (2003). Laugh and Learn: Ninety-five ways to use humour for more effective teaching and learning. New York: AMACOM Books.

Thambi Jose. S Franklin and John, Sagi. (2012). Humor in College Classrooms. In conference proceedings of Education for Global Excellence, Thiruvanathapuram: Mar Theophilus Training College.

Thambi Jose, S. Franklin, Samikkanu Jabamoney Ishak Samuel, Manonmani Devi Annamalai and Muniisvaran Kumar. (2019). A Study on Evaluating the Pedagogical Knowledge of School Teachers, Journal of Educational and Social Research, Vol.9, No.3, Nov.2019, Pg.194-202. (E-ISSN 2240-0524)

Torok,S., Mc Morris, R., \& Lin,W. (2004). Is humour an appreciated teaching tool?. College Teaching,52(1), pp14-20.

Windley,C. (1976). Teaching $\mathcal{E}$ Learning with magic. Acropolis Books; Washington 